\title{
Limb Swinging in Elephants and Giraffes and Implications for the Reconstruction of Limb Movements and Speed Estimates in Large Dinosaurs
}

\author{
Andreas Christian ${ }^{1}$, Reinert H. G. Müller ${ }^{2}$, Gundula Christian ${ }^{1}$ \& Holger Preuschoft $^{3}$
}

With 4 figures and 3 tables

\begin{abstract}
Speeds of walking dinosaurs that left fossil trackways have been estimated using the stride length times natural pendulum frequency of the limbs. In a detailed analysis of limb movements in walking Asian elephants and giraffes, however, distinct differences between actual limb movements and the predicted limb movements using only gravity as driving force were observed. Additionally, stride frequency was highly variable. Swing time was fairly constant, but especially at high walking speeds, much shorter than half the natural pendulum period. An analysis of hip and shoulder movements during walking showed that limb swinging was influenced by accelerations of hip and shoulder joints especially at high walking speeds. These results suggest an economical fast walking mechanism that could have been utilised by large dinosaurs to increase maximum speeds of locomotion. These findings throw new light on the dynamics of large vertebrates and can be used to improve speed estimates in large dinosaurs.
\end{abstract}

Key words: Dinosaurs, sauropods, speed, locomotion, biomechanics, functional morphology.

\section{Zusammenfassung}

Geschwindigkeiten gehender Dinosaurier, die fossile Fährten hinterlassen haben, wurden als Produkt aus Schrittlänge und natürlicher Pendelfrequenz der Beine abgeschätzt. Eine detaillierte Analyse der Beinbewegungen von gehenden Asiatischen Elefanten und Giraffen offenbarte allerdings klare Unterschiede zwischen den tatsächlichen Extremitätenbewegungen und den Bewegungen, die zu erwarten wären, wenn die Gravitation die einzige treibende Kraft darstellte. Zudem erwies sich die Schrittfrequenz als hochgradig variabel. Die Schwingzeit der Gliedmaßen war recht konstant, aber besonders bei hohen Gehgeschwindigkeiten viel kürzer als die halbe natürliche Pendelperiode der Extremitäten. Eine Analyse der Bewegungen der Hüft- und Schultergelenke während des Gehens zeigte, daß das Schwingen der Gliedmaßen durch Beschleunigungen dieser Gelenke beeinflußt wurde, insbesondere bei hohen Gehgeschwindigkeiten. Die Resultate legen einen ökonomischen Mechanismus für schnelles Gehen nahe, der von großen Dinosauriern zur Erhöhung der Höchstgeschwindigkeiten eingesetzt worden sein könnte. Die Ergebnisse werfen neues Licht auf die Dynamik großer Wirbeltiere. Sie können zu Verbesserungen in den Schätzungen der Fortbewegungsgeschwindigkeiten großer Dinosaurier eingesetzt werden.

Schlüsselwörter: Dinosaurier, Sauropoden, Geschwindigkeit, Fortbewegung, Biomechanik, Funktionelle Morphologie.

\section{Introduction}

Speeds of locomotion of dinosaurs can be estimated from comparative studies among recent vertebrates and from the laws of mechanics. Maximum speeds can be estimated roughly from morphological traits like limb proportions and modelled strength of skeletal elements (Coombs 1978, Alexander 1985a, 1989a, Farlow et al. 1995; but see also Alexander 1996). Speeds can also be estimated from fossil trackways (Alexander 1976, 1985a, 1989a, Thulborn 1990). The usually narrow trackways of dinosaurs (Lockley 1991, Thulborn 1990, Lockley \& Hunt 1995) indicate that limb movements were restricted to parasagittal planes like most mammals. Additionally, a mammal-like limb posture for most dinosaurs can be modelled from skeletal features (Charig 1979, Bakker 1986, Paul 1987, 1988, Weishampel et al. 1990, Fastovsky \& Weishampel 1996; but see also Johnson \& Ostrom 1995). Given a set of tracks and assuming mammal like limb movements, relationships among stride length, hip height, and speed can be applied to

\footnotetext{
${ }^{1}$ Museum für Naturkunde, Institut für Paläontologie, Invalidenstr. 43, 10115 Berlin, Germany.

2 FIBUS, Arnheimer Str. 120, 40489 Düsseldorf, Germany.

${ }^{3}$ Ruhr-Universität Bochum, Fakultät für Medizin, Anatomisches Institut, Universitätstr. 150, 44780 Bochum, Germany. Received January 1999, accepted June 1999
} 
predict the approximate speed of the track-maker (Alexander 1976).

Most fossil trackways of large dinosaurs indicate a walking gait (Thulborn 1990). In this paper "walking" is used for any gait with a duty factor (fraction of time a foot is placed on the ground during a stride) above 0.5 in all limbs (in accordance with Hildebrand (1985)). It has been suggested that walking speeds from fossil trackways can be estimated by multiplying stride length with stride frequency (Demathieu 1986). Because of the relatively low muscle forces compared with body weight in large vertebrates (Alexander 1985b, Demes \& Günther 1989; Preuschoft et al. 1994), minimal muscle force to accelerate the limbs can be expected. During walking, passive limb swinging driven by gravity would minimise force and energy expenditure (Hildebrand 1985). Therefore, in a simple model of a stiff limb swinging about a fixed pivot, stride frequency should be similar to the natural pendulum frequency of the limb. Moderate deviations of the pendulum frequency up to some ten percent are suggested by more sophisticated models of limb swinging during walking taking movements of the proximal joints and elastic properties of the limb into account (Mochon \& McMahon 1980a, b, McGreer 1990, 1992, Witte et al. 1991, 1995, Alexander 1995).

Stride frequency has indeed been shown to be similar to the natural pendulum frequency of the limbs in several walking vertebrates (Hildebrand 1985). However, considerable variation in stride frequency of walking animals does occur. For speed estimates based on estimated stride frequencies, a deeper understanding of the mechanisms of limb swinging is needed to increase the accuracy.

Like most large dinosaurs, elephants have massive and pillar-like limbs. Limb swinging in elephants is restricted to parasagittal planes. Addi- tionally, like large dinosaurs, elephants do not gallop. Therefore, elephants are suitable for modelling the limb mechanics of large dinosaurs (Christiansen 1997). In this study, the swinging behaviour of the limbs of Asian elephants was analysed during walking at different speeds. Stride frequency was compared to the natural pendulum frequency of the limbs at different speeds. The role that acceleration of hip and shoulder joints play in accelerating the swinging limbs was examined, as well. Movements of hip and shoulder joints were also studied in walking giraffes to examine the applicability of a model derived from elephants to other taxa. The results are discussed with respect to the mechanics of limb movements and speed estimates in large dinosaurs.

\section{Methods}

Four adult Asian elephants (Elephas) of similar size were studied at the Zoo Krefeld, Germany. The animals were guided by their trainer who walked or ran in front of them along a straight line ("race track") of about $30 \mathrm{~m}$ length. The walking speeds of the elephants ranged between $0.5 \mathrm{~m} / \mathrm{s}$ and $2.8 \mathrm{~m} / \mathrm{s}$. Sequences were recorded with the help of the picCOLOR image analysis system (see below). Additional sequences were recorded from the elephants walking freely around in the enclosure. Stride period, duration of the swing phase (swing time), and duration of the support phase (support time) of single limbs were determined in all sequences. Speed of locomotion could only be determined from the videos for elephants moving along the race track.

In order to analyse the limb movements in more detail, in one individual white markers were glued on the skin at several positions on the limbs, especially at the locations of the major joints (Fig. 1). In the analysis of limb swinging,

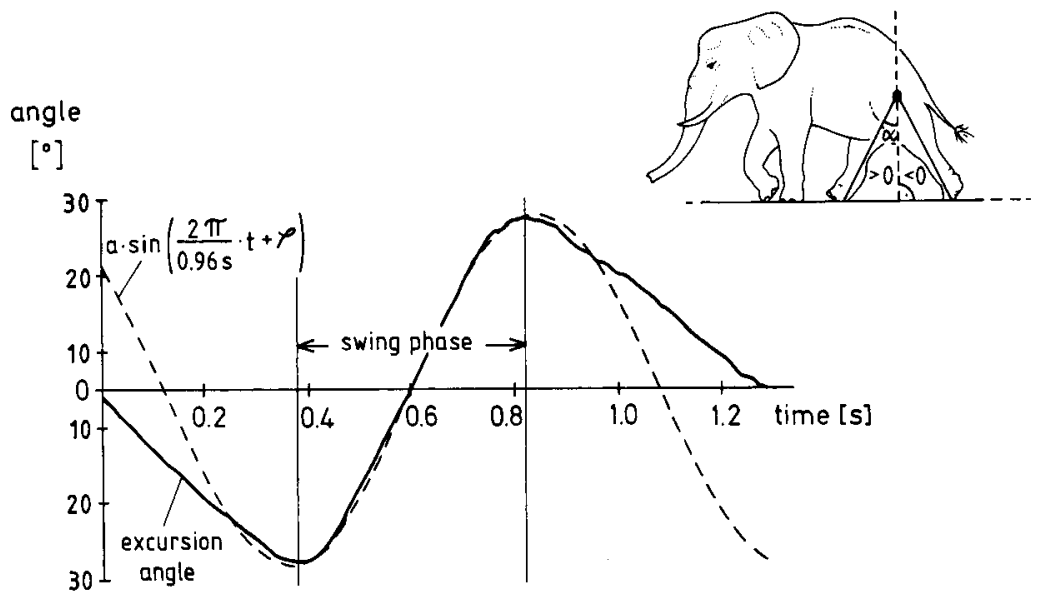

Fig. 1. Excursion angle $\alpha$ of the right hindlimb of an elephant relative to the vertical during a walking stride at a speed of about $1.6 \mathrm{~m} / \mathrm{s}$ (solid line) compared to a sine-function (dotted line). $t$, time; a, $\varphi$, constants used to make the sine-function fit to the excursion angle during the swing phase. 
the hindlimb was represented by the line that connected the marker fixed at the hip joint and a marker positioned closely above the ankle joint. In side-view, the centre of mass of the limb (CM) was located close to this line during the whole stride.

Skin displacements relative to underlying bones were large at knees, elbows, and shoulders, but small enough at hips, at the distal part of the lower hindlimb, and at the hindfeet to conduct a quantitative analysis of angular displacements of the hindlimbs about the hip joints and to analyse the movements of the hip joints during a stride. Due to the large displacements of the skin relative to the underlying bones in the forelimbs, especially at the shoulder joints, angular displacements of the forelimbs and movements of the shoulder joints were not quantified.

Additionally, hip and shoulder movements of two adult giraffes were studied at the Allwetterzoo Münster, Germany. The animals walked along a straight wall in their spacious enclosure without being influenced by any human. The mean walking speed of the two animals was close to $1.1 \mathrm{~m} / \mathrm{s}$ and $1.3 \mathrm{~m} / \mathrm{s}$, respectively, with little variation. Reference points (markers) on the animals were identified with the help of the skin pattern.

The "picCOLOR" image analysis system, developed at F.I.B.U.S. research institute (Forschungs-Institut für Bildverarbeitung, Umwelttechnik \& Strömungstechnik), has been used for all video sequence acquisition and post processing. "picCOLOR" is a PC-compatible computer system incorporating a powerful frame grabber, an imaging processor board, and a modular interactive imaging software. A black/white Hitachi KPM1ek CCD camera was used at a geometrical image resolution of $768 \times 512$ picture elements (pixel). 64 MBytes of imaging memory allowed the acquisition of 7 seconds real time sequences at $25 \mathrm{~Hz}$. Every half-frame was used in the analysis in order to achieve a image rate of $50 \mathrm{~Hz}$. This procedure yielded only half the spatial resolution in y-direction (the vertical) as in using full frames. The camera was installed at a distance of $20 \mathrm{~m}$ from the elephants and $30 \mathrm{~m}$ from the giraffes perpendicular to the direction of locomotion. Several image sequences were stored on hard disk for later processing.

In some sequences, the background was graphically removed by mathematically subtracting a reference image. For the small numbers of simple markers on the skin of an elephant the object tracking method was used. Depending on the visibility and contrast of the markers, object tracking was performed either automatically or by manually clicking on the marker with the mouse pointer. The position of a marker was determined with subpixel accuracy by calculating the centre of gravity of its pixel area. This process revealed the paths of selected spots of the animals in vectorized form. For the net giraffe pattern, a cross correlation algorithm was used to determine displacements of spots on the skin between two images.

The excursion angle of the hindlimbs of the elephant relative to the vertical was determined by representing the limb by a straight line connecting the marker at the hip joint with a marker that was fixed closely above the ankle joint. In side-view, the centre of mass of the limb was located close to this line during the whole stride. In the elephants, the giraffes, and the Tendaguru-sauropods discussed here, the locations of the centre of mass and the natural pendulum periods of the limbs were estimated from limb proportions. For this purpose, scaled rubber models of the limbs were cut. In the giraffes, the diameters of the lower limbs were increased in order to compensate for the high fraction of bone. Otherwise, constant density was assumed. With a scaled model, the location of the centre of mass of a limb can be directly determined using the method described by Alexander (1989a). The natural pendulum periods of the models were measured by letting them swing friction-free around transversal axes through the positions of hip and shoulder joints, respectively. To obtain the pendulum period of the full sized limb, the pendulum period of the model has to be multiplied by the square root of the scaling factor.

The estimated natural pendulum periods and frequencies were in accordance to results of Hildebrand (1985) on large recent vertebrates and Demathieu (1986) on dinosaurs. Although the flexion of a limb changed during a stride and was slightly different at different speeds, the pendulum period was little affected by these changes and nearly independent of walking speed.

\section{Results}

In the elephants, stride frequency varied considerably, spanning more than a factor of 3 in all specimens. It ranged from $0.34 / \mathrm{s}$ to $1.19 / \mathrm{s}$ in the individual with the highest variation. All elephants frequently utilised stride frequencies far 
above the natural pendulum frequency of the limbs, which was $0.55 \pm 0.05 / \mathrm{s}$ for all examined limbs. Support time was variable, spanning a factor of 4 or more in all individuals in the hindlimbs as well as in the forelimbs. Swing time, however, was much less variable, ranging from $0.36 \mathrm{~s}$ to $0.6 \mathrm{~s}$ in the forelimbs and from $0.38 \mathrm{~s}$ to $0.64 \mathrm{~s}$ in the hindlimbs in the individual showing the widest range. Shorter periods were generally utilised at lower speeds and were associated with short stride lengths, as typical for terrestrial locomotion (Alexander 1976, McMahon \& Bonner 1983). Table 1 presents the data collected from the hindlimbs of two equally sized elephants. These data were used to compare the actual speed of locomotion with speed estimates from the literature (see discussion).

During the swing phase, angular displacements of the hindlimbs approximately fitted sinefunctions (Fig. 1), as expected for limbs that move like pendula driven by gravity. The swing time, however, was considerably shorter than half the natural pendulum period $(\mathrm{T}=1.75 \pm 0.10 \mathrm{~s}$, $\mathrm{T} / 2=0.88 \pm 0.05 \mathrm{~s})$ of the limbs, especially during fast walking (Table 1).

As expected (see discussion), during the support phase, variability of support time, angular displacements of the limbs, and vertical hip displacements were very different from a gravitydriven pendulum model of limb motion. The hip joints experienced considerable acceleration during a stride. During the first $30 \%-40 \%$ of the swing phase, the hip joint of the swinging hindlimb was accelerated upward (Fig. 2). Afterwards, at the middle of the swing phase, it was accelerated downward. These hip accelerations increased with stride frequency, but were difficult to quantify at low speeds. At high walking speeds upward hip accelerations were nearly $10 \mathrm{~m} / \mathrm{s}^{2}$, close to the acceleration due to gravity $\mathrm{g}=9.81 \mathrm{~m} / \mathrm{s}^{2}$. Forward and backward accelerations of the hip joints were much lower and difficult to quantify because of errors in locating the position of the joints. Although the position of the shoulder joints could not be reconstructed in walking elephants, the reduction of swing time at high walking speeds and the shoulder movements in giraffes (see below) support the idea of a similar acceleration mechanism in the forelimbs.

Different from elephants, in giraffes, speed and stride frequency showed little variation, probably because the giraffes were not guided or chased. Mean values and standard deviations are presented in Table 2. Speed ranged from $1.12 \mathrm{~m} / \mathrm{s}$ to $1.84 \mathrm{~m} / \mathrm{s}$ in the adult and from $0.93 \mathrm{~m} / \mathrm{s}$ to $1.68 \mathrm{~m} / \mathrm{s}$ in the semi-adult individual. Stride period ranged from $1.58 \mathrm{~s}$ to $2.26 \mathrm{~s}$ in the adult and from $1.58 \mathrm{~s}$ to $2.04 \mathrm{~s}$ in the semi-adult giraffe. Like elephants, swing time was more constant than support time and considerably shorter than half the natural pendulum periods of the limbs. In the adult specimen support time ranged from $0.90 \mathrm{~s}$ to $1.36 \mathrm{~s}$ and swing time from $0.68 \mathrm{~s}$ to $0.74 \mathrm{~s}$. In the semi-adult specimen support time ranged from $1.02 \mathrm{~s}$ to $1.56 \mathrm{~s}$ and swing time from $0.56 \mathrm{~s}$ to $0.64 \mathrm{~s}$. The natural pendulum period was $\mathrm{T}=1.83 \pm 0.10 \mathrm{~s}$ in the adult giraffe (hip height $\mathrm{h}=2.04 \mathrm{~m}$ ) and $\mathrm{T}=1.66 \pm 0.10 \mathrm{~s}$ in the semi-adult giraffe $(\mathrm{h}=1.64 \mathrm{~m})$.

In giraffes, hips moved in a similar manner as in elephants. Different from elephants, movements of the shoulder joints could be determined. Like the hip joints, the shoulder joints accelerated upward during the first part of the swing phase. The range of error in determining the location of the shoulder joints, however, was still too large to quantify the magnitudes of shoulder joint accelerations.

\section{Discussion}

\section{The variation of stride frequency}

Theoretical considerations concerning the energetics of locomotion and simple models of limb movements in bipeds as well as in quadrupeds suggest stride frequencies not far away from the natural pendulum frequency of the limbs during walking (Mochon \& McMahon 1980a, b, Hoyt \& Taylor 1981, Alexander 1989b, 1995, McGreer 1990, 1992, Witte et al. 1991, 1995, Preuschoft \& Günther 1994, Preuschoft et al. 1994). Although the range of stride frequencies in walking elephants was found to overlap with the natural pendulum frequency of the limbs, in accordance to findings in other vertebrates (Hildebrand 1985), the variation of stride frequency was high. At low speeds, stride frequency was considerably below the natural pendulum frequency whereas it was much higher at high walking speeds (Table 1). The high variation of stride frequencies among elephants was supported by data collected from videos showing elephants in their natural habitats. The more constant stride frequencies observed in giraffes were close to the natural pendulum frequencies of the limbs (Table 2). However, there was little variation of speed in the giraffes. Videos showing giraffes in 
Table 1

The walking speed $v$ of two same sized elephants (specimen 1 and specimen 2) compared to speed estimates after the method of Demathieu (1986): $\mathrm{v}^{\prime}$, and Alexander (1976): $\mathrm{v}^{\prime \prime}$, respectively. T, stride period; $T_{\mathrm{su}}$, support time; $\mathrm{T}_{\mathrm{sw}}$, swing time; $\mathrm{s}$, stride length; $h$, hip height; $s / h=$ stride length/hip height (relative stride length). Bold letters: the actual speed deviates less than $50 \%$ from the estimated speed.

\begin{tabular}{|c|c|c|c|c|c|c|c|c|}
\hline specimen & $\frac{\mathrm{T}}{\mathrm{s}}$ & $\frac{\mathrm{T}_{\mathrm{su}}}{\mathrm{s}}$ & $\frac{T_{\mathrm{sw}}}{\mathrm{s}}$ & $\frac{\mathrm{s}}{\mathrm{m}}$ & $\mathrm{s} / \mathrm{h}$ & $\frac{\mathrm{v}}{\mathrm{m} / \mathrm{s}}$ & $\frac{\mathrm{v}^{\prime}}{\mathrm{m} / \mathrm{s}}$ & $\frac{\mathrm{v}^{\prime \prime}}{\mathrm{m} / \mathrm{s}}$ \\
\hline 1 & $0.84 \pm 0.02$ & $0.48 \pm 0.02$ & $0.36 \pm 0.02$ & $3.24 \pm 0.05$ & 2.16 & $3.86 \pm 0.11$ & 1.85 & 3.47 \\
\hline 1 & $0.88 \pm 0.02$ & $0.50 \pm 0.02$ & $0.38 \pm 0.02$ & $3.09 \pm 0.05$ & 2.06 & $3.51 \pm 0.10$ & 1.77 & 3.20 \\
\hline 1 & $0.90 \pm 0.02$ & $0.52 \pm 0.02$ & $0.38 \pm 0.02$ & $3.23 \pm 0.05$ & 2.15 & $3.59 \pm 0.10$ & 1.85 & $\mathbf{3 . 4 5}$ \\
\hline 1 & $0.94 \pm 0.02$ & $0.58 \pm 0.02$ & $0.36 \pm 0.02$ & $2.90 \pm 0.05$ & 1.93 & $3.09 \pm 0.08$ & 1.66 & 2.88 \\
\hline 2 & $1.00 \pm 0.02$ & $0.62 \pm 0.02$ & $0.38 \pm 0.02$ & $2.85 \pm 0.05$ & 1.90 & $2.85 \pm 0.08$ & 1.63 & 2.80 \\
\hline 1 & $1.02 \pm 0.02$ & $0.64 \pm 0.02$ & $0.38 \pm 0.02$ & $3.08 \pm 0.05$ & 2.05 & $3.02 \pm 0.08$ & 1.76 & 3.19 \\
\hline 1 & $1.30 \pm 0.02$ & $0.86 \pm 0.02$ & $0.44 \pm 0.02$ & $2.54 \pm 0.05$ & 1.69 & $1.95 \pm 0.05$ & 1.45 & 2.31 \\
\hline 2 & $1.36 \pm 0.02$ & $0.90 \pm 0.02$ & $0.46 \pm 0.02$ & $2.52 \pm 0.05$ & 1.68 & $1.85 \pm 0.05$ & 1.44 & 2.28 \\
\hline 1 & $1.48 \pm 0.02$ & $1.00 \pm 0.02$ & $0.48 \pm 0.02$ & $2.64 \pm 0.05$ & 1.76 & $1.78 \pm 0.04$ & 1.51 & 2.46 \\
\hline 1 & $1.52 \pm 0.02$ & $1.00 \pm 0.02$ & $0.52 \pm 0.02$ & $2.46 \pm 0.05$ & 1.64 & $1.62 \pm 0.04$ & 1.41 & 2.19 \\
\hline 1 & $1.58 \pm 0.02$ & $1.10 \pm 0.02$ & $0.48 \pm 0.02$ & $2.42 \pm 0.05$ & 1.61 & $1.53 \pm 0.04$ & 1.38 & 2.13 \\
\hline 1 & $1.72 \pm 0.02$ & $1.20 \pm 0.02$ & $0.52 \pm 0.02$ & $2.19 \pm 0.05$ & 1.46 & $1.27 \pm 0.03$ & 1.25 & 1.80 \\
\hline 1 & $1.72 \pm 0.02$ & $1.20 \pm 0.02$ & $0.52 \pm 0.02$ & $2.33 \pm 0.05$ & 1.55 & $1.35 \pm 0.03$ & 1.33 & 2.00 \\
\hline 2 & $1.76 \pm 0.02$ & $1.24 \pm 0.02$ & $0.52 \pm 0.02$ & $2.33 \pm 0.05$ & 1.55 & $1.32 \pm 0.03$ & 1.33 & 2.00 \\
\hline 2 & $1.98 \pm 0.02$ & $1.44 \pm 0.02$ & $0.54 \pm 0.02$ & $1.64 \pm 0.05$ & 1.09 & $0.83 \pm 0.02$ & 0.94 & 1.11 \\
\hline 1 & $2.08 \pm 0.02$ & $1.54 \pm 0.02$ & $0.54 \pm 0.02$ & $1.98 \pm 0.05$ & 1.32 & $0.95 \pm 0.02$ & 1.13 & 1.52 \\
\hline 2 & $2.26 \pm 0.02$ & $1.66 \pm 0.02$ & $0.60 \pm 0.02$ & $2.41 \pm 0.05$ & 1.61 & $1.07 \pm 0.03$ & 1.38 & 2.12 \\
\hline 1 & $2.56 \pm 0.02$ & $1.98 \pm 0.02$ & $0.58 \pm 0.02$ & $1.50 \pm 0.05$ & 1.00 & $0.59 \pm 0.02$ & 0.86 & 0.96 \\
\hline 1 & $2.76 \pm 0.02$ & $2.14 \pm 0.02$ & $0.62 \pm 0.02$ & $2.05 \pm 0.05$ & 1.37 & $0.74 \pm 0.03$ & 1.17 & 1.61 \\
\hline
\end{tabular}

their natural habitat also prove considerable variation of stride frequency during walking.

Therefore, estimating the stride frequency of a fossil track-maker by estimating the natural pendulum frequency of its limbs cannot be expected to give precise results. A possible error of a factor of 2 in each direction should be taken into account. Elephants as well as giraffes tended to prefer stride frequencies close to or a little bit below the estimated natural pendulum frequencies of the hindlimbs, if they walked undisturbed over a long distance. However, from a short preserved trackway it can be difficult or even impossible to derive whether an animal was walking in a comfortable way or relatively slow or fast. Whereas stride frequencies close to the natural pendulum frequencies of the limbs seem to be preferred by animals that walk undisturbed over a long distance, considerably higher frequencies can be expected at high walking speeds and considerably lower frequencies at low walking speeds. If sufficient information is available to decide whether an animal was walking at a relatively low or high speed, the increase of stride frequency with speed should be taken into account for estimating the stride frequency more precisely. Very long trackways, however, might indicate comfortable walking speeds with stride frequencies not too far away from the natural pendulum frequency of the limbs.

Speed estimates based on estimates of stride frequencies are as good or bad as the estimated stride frequencies. In the elephants and giraffes studied, speed estimates based on estimates of the natural pendulum frequency of the hindlimbs are presented in Table 1 and Table 2. This method gives good results at mean walking speeds but poor results at extreme speeds, especially at high speeds. In contrast, the equation proposed by Alexander (1976)

$$
v=0.25 \cdot \sqrt{\mathrm{g}} \cdot \frac{\mathrm{s}^{1.67}}{\mathrm{~h}^{1.17}}
$$

( $v$ : estimated speed; $g=9.81 \mathrm{~m} / \mathrm{s}^{2}$, acceleration due to gravity; s: stride length; h: height of hip from the ground) yielded best results at high walking speeds. The actual speed of locomotion was usually within $\pm 50 \%$ of the speed estimate

Table 2

Locomotion parameters of two giraffes with hip heights of $2.04 \mathrm{~m}$ (specimen 1) and $1.64 \mathrm{~m}$ (specimen 2), mean values \pm standard deviations. Speeds were calculated from mean values of stride period and stride length. Symbols as in Table 1.

\begin{tabular}{|c|c|c|c|c|c|c|c|c|}
\hline specimen & $\frac{\mathrm{T}}{\mathrm{s}}$ & $\frac{\mathrm{T}_{\mathrm{su}}}{\mathrm{s}}$ & $\frac{\mathrm{T}_{\mathrm{sw}}}{\mathrm{s}}$ & $\frac{\mathrm{s}}{\mathrm{m}}$ & $\mathrm{s} / \mathrm{h}$ & $\frac{\mathrm{v}}{\mathrm{m} / \mathrm{s}}$ & $\frac{\mathrm{v}^{\prime}}{\mathrm{m} / \mathrm{s}}$ & $\frac{\mathrm{v}^{\prime \prime}}{\mathrm{m} / \mathrm{s}}$ \\
\hline $\begin{array}{l}1 \\
2\end{array}$ & $\begin{array}{l}2.00 \pm 0.20 \\
1.95 \pm 0.23\end{array}$ & $\begin{array}{l}1.28 \pm 0.21 \\
1.34 \pm 0.20\end{array}$ & $\begin{array}{r}0.71 \pm 0.02 \\
0.60 \pm 0.03\end{array}$ & $\begin{array}{l}2.60 \pm 0.20 \\
2.20 \pm 0.28\end{array}$ & $\begin{array}{l}1.27 \pm 0.10 \\
1.34 \pm 0.17\end{array}$ & $\begin{array}{l}1.30 \\
1.13\end{array}$ & $\begin{array}{l}1.42 \\
1.33\end{array}$ & $\begin{array}{l}1.68 \\
1.64\end{array}$ \\
\hline
\end{tabular}


compared to a maximum error of about $100 \%$ if the speed was estimated from the natural pendulum frequency of the limbs. Equation (1) has been shown to give good results for a variety of walking and running animals (Alexander 1976, 1989a). Because of the uncertainty in estimating the stride frequency from a trackway, this method seems generally more reliable for speed estimates than the method based on estimates of the natural pendulum frequency of the limbs. Additionally, there might be considerable uncertainty in modelling the natural pendulum frequencies of the limbs of extinct vertebrates and natural pendulum frequencies might be very different in forelimbs and hindlimbs raising the question which pair of limbs has to be used for speed estimates.

\section{Swing time and support time in relation to stride frequency}

Higher variation of support time than swing time can be expected. During the support phase, the foot is placed on a more or less fixed position on the ground whereas the hip joint travels forward with a rather constant speed. Therefore, a more or less linear progression of the angle between the limb and the vertical is predicted, as was indeed observed (Fig. 1). Support time is simply determined by the total angle the limb covers during the support phase divided by the angular velocity of the limb. This period will not necessarily be closely related to the swing time of the opposite limb (Fig. 1).

The duration of the swing phase was much more constant than the duration of the support phase. At low speeds, it was close to half the natural pendulum period. At high walking speeds, swing time was considerably less than half

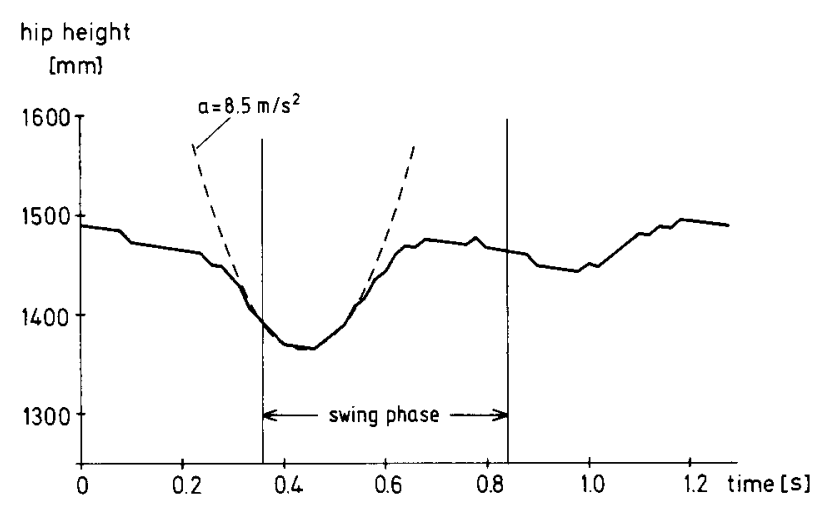

Fig. 2. Variation of hip height (solid line) during the stride presented in Fig. 1. During the first part of the swing phase, the movement of the hip joint fits to an upward acceleration of $8.5 \mathrm{~m} / \mathrm{s}^{2}$ (dotted line) the natural pendulum period indicating more active force input to the limbs since shorter periods mean higher angular accelerations of the swinging limbs. Especially at high walking speeds, either additional force must be exerted upon the limbs by muscles and elastic tissues or the pivots of the swinging limbs must be accelerated (see below).

\section{Accelerations of the proximal limb joints}

The natural pendulum period $\mathrm{T}$ of a limb can be calculated by:

$\mathrm{T}=2 \cdot \pi \cdot \sqrt{\frac{\mathrm{I}}{\mathrm{m} \cdot \mathrm{g} \cdot \mathrm{d}}}$

( $\mathrm{m}$, mass of the limb, I, moment of inertia about the hip joint, g, acceleration due to gravity, d, distance between the hip joint and the centre of mass of the limb). The natural pendulum frequency $\mathrm{f}$ is the inverse of the natural pendulum period $\mathrm{T}$ :

$\mathrm{f}=\frac{1}{\mathrm{~T}}=\frac{1}{2 \cdot \pi} \cdot \sqrt{\frac{\mathrm{m} \cdot \mathrm{g} \cdot \mathrm{d}}{\mathrm{I}}}$

Accelerations of the pivot alter the period of a suspended pendulum thereby affecting the swinging behaviour of a limb (Mochon \& McMahon 1980a, b, Alexander 1995, Fig. 3). If the pivot is accelerated upward by an acceleration a, then the period $\mathrm{T}$ and frequency $\mathrm{f}$ of a pendulum are altered according to

$$
\begin{aligned}
& T=2 \cdot \pi \cdot \sqrt{\frac{I}{m \cdot(g+a) \cdot d}}, \\
& f=\frac{1}{T}=\frac{1}{2 \cdot \pi} \cdot \sqrt{\frac{m \cdot(g+a) \cdot d}{I}} .
\end{aligned}
$$

Equations (4) and (5) are derived from equations (2) and (3) by adding the pivot acceleration a to the acceleration due to gravity g. This increase in total acceleration means that the observed upward acceleration of the hip joint during the first part of the swing phase positively affects the angular acceleration and, therefore, the angular velocity of the hindlimb. In the middle of the swing phase, the downward acceleration of the hip joint had little effect on the angular velocity because the centre of mass of the limb was more or less in line with the direction of the acceleration during this part of the swing phase. In the sequences in which the upward acceleration of the hip joint could be quantified, the acceleration was sufficiently high so that, un- 

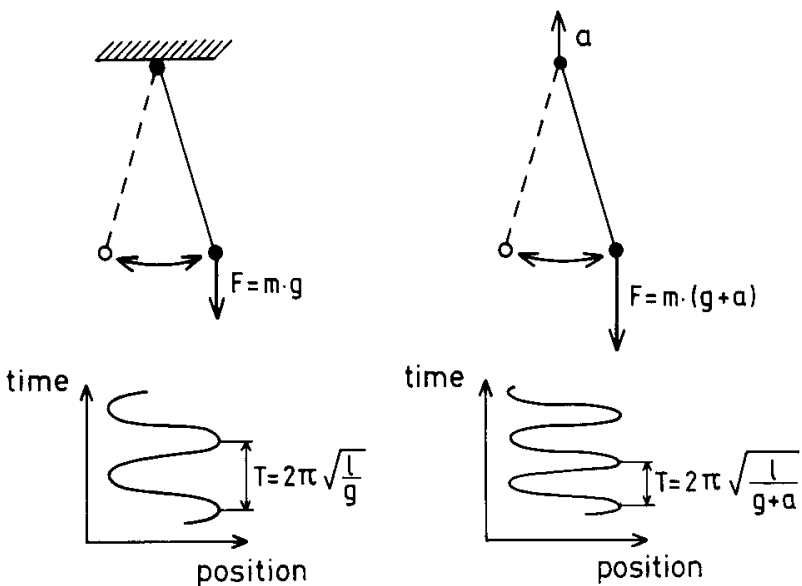

Fig. 3. With an upward accelerating pivot, the period $\mathrm{T}$ of a pendulum is reduced. $\mathrm{F}$, weight force; $\mathrm{m}$, mass; $\mathrm{g}$, acceleration due to gravity; a, upward acceleration of the pivot; 1 , chord length

til angular velocity was reduced during the last third of the swing phase, the hindlimb swinging could be explained as a pendulum-like movement that was driven mostly by gravity and the upward acceleration of the hip joint with little input of muscle force. During the last third of the support phase, however, force from muscles or tendons is necessary to support the deceleration of the limbs. In the example given in Fig. 2, the upward acceleration of the hip joint at the first part of the swing phase was $a=8.5 \mathrm{~m} / \mathrm{s}^{2}$. An upward acceleration of this magnitude would increase the frequency of a pendulum by a factor of about 1.37, if it was constant during the complete swing phase. There may be an additional force and energy input to the swinging hindlimbs by horizontal accelerations of the hip joints which could not be examined here due to the problems in quantifying horizontal hip accelerations mentioned above.

The additional results on giraffes indicate that the mechanism of supporting the limb swinging by accelerations of the proximal limb joint is neither restricted to elephants nor to the hindlimbs. It should be mentioned here that in the forelimbs the pivot is not identical with the prox- imal joint (shoulder joint) if the shoulder blade is regarded as part of the swinging limb. Due to movements of the scapula relative to the thorax, the pivot of a forelimb is located somewhat above the shoulder joint and might shift its position during a stride. Nevertheless, movements of the free extremity can be mechanically described as movements of a physical pendulum with the shoulder joint as a mobile pivot.

\section{Large dinosaurs: efficient walkers}

The hip accelerations observed in large mammals may result from forces transmitted to the pelvis from the opposite hindlimb in combination with hip rotations. The accelerations of the shoulder joints are mainly achieved by rotations of the scapulae. In most large dinosaurs, however, both hip joints are connected firmly and are located rather closely together and the shoulder girdles appear much more rigid than in mammals. Therefore, rotation of the pelvic girdle and movements in the pectoral girdle could not have been utilised for accelerating hip and shoulder joints in exactly the same way as described above for large mammals. However, forces transmitted by the supporting hindlimb and forelimb, respectively, must have accelerated the shoulder and hip joint of the swinging opposite limb. Consequently, swing times were decreased similar to elephants and giraffes.

With ground-reaction forces approximately in line with the supporting hindlimb, as in large, recent vertebrates (Biewener 1989, 1990), the hip joint of the swinging hindlimb of a dinosaur was accelerated backward and upward in the first half of the swing phase, and forward and upward in the second half of the swing phase. This must have been also true in bipeds where no additional ground-reaction forces were exerted on the body by the forelimbs. With a typical bimodal time course of the ground reaction forces (Fig. 4), hip acceleration magnitudes would have been large at extreme excursion angles thereby

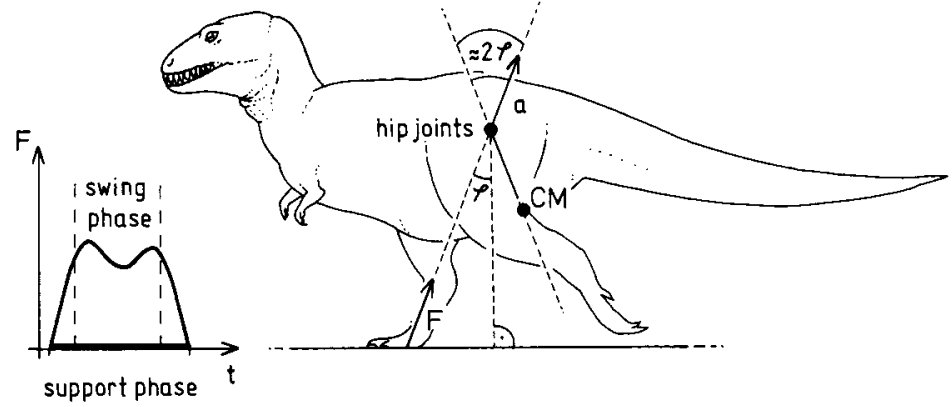

Fig. 4. A walking large dinosaur. With the groundreaction-force $\mathbf{F}$ approximately in line with the supporting limb the body experiences an acceleration $\mathbf{a}=\mathbf{F} / \mathbf{m}$ ( $\mathrm{m}$, body mass) in the direction of the ground reaction force. $\mathrm{CM}$, centre of mass of the swinging limb; $\varphi$, excursion angle; $t$, time 
increasing the angular accelerations of the swinging hindlimb as observed in elephants and giraffes. Additionally, the large angle between the force acting on the hip joint and the hindlimb (about twice the angle between the direction of gravity and the chord in a pendulum with a fixed pivot), further increased the torque experienced by the swinging hindlimb and thereby its angular acceleration.

Accelerations of hip and shoulder joints have been shown to be effective in transmitting force and energy on the moving limbs in sprawlers, as well (Christian 1995), indicating that this mechanism is widespread among vertebrates and not restricted to mammals with parasagittal limb movements.

In large walking dinosaurs swing time probably was well below half the natural pendulum period of the limbs, especially at high walking speeds, as observed in elephants. A shortening of the swing phase is advantageous not only for attaining high speeds but also for increased economy. With a given support time, shortening of the swing time decreases the average force applied by the foot to the ground. As force is reduced, muscle mass can be reduced. Less muscle mass means less total body mass. With less body mass, the total energy consumption of an animal is reduced at rest, as well as during locomotion (Taylor 1977, Taylor et al. 1980, 1982, SchmidtNielsen 1984, Kram \& Taylor 1990). At a given stride frequency, a shorter swing time implies a longer support time. Longer support times spread the force necessary to carry the body weight over a long period and have been shown to decrease the cost of transport in running vertebrates (Kram \& Taylor 1990). A simple relationship between time of force application and cost for transport, however, has not been found for walking (Taylor 1994).

Shortening the swing time of a limb by accelerating hip and shoulder joints helps to explain how large vertebrates manage to move cheaply even with massive limbs, as has been observed in African elephants (Langman et al. 1995).

\section{Estimated speeds of some Tendaguru-dinosaurs}

In some forms, like sauropods, a variety of preserved trackways have been found (Lockley 1991, Thulborn 1990, Lockley \& Hunt 1995). Different trackways of the same kind of trackmaker can be compared. In those trackways with the shortest stride lengths, stride frequency can be assumed to have been much lower than it was in the trackways with the longest. While stride lengths matches the natural pendulum frequency somewhere in between.

Thulborn (1990) found an average relative stride length (= stride length divided by limb length which is approximately equal to stride length divided by hip height, $\mathrm{s} / \mathrm{h}$, in the hindlimbs) of 0.93 in a sample of sauropod trackways. This is considerably less than the relative stride length of elephants and giraffes at comfortable speeds (Table 1). There is some uncertainty in estimating the relative stride length of an extinct track-maker because the hip height has to be reconstructed. This could lead to minor errors in the estimates of comfortable walking speeds. Thulborn (1990) estimates the hip height $h$ of a sauropod as four times footprint length leading to a hip height above $4.4 \mathrm{~m}$ in Brachiosaurus. With extended knees, the large Berlin specimen SII, however, has a hip height of just about $3.5 \mathrm{~m}$. The hip heights estimated by Thulborn (1990) might be $10 \%$ or $20 \%$ too high. However, a relative stride length of 1.0 seems a realistic estimate for a comfortable walking sauropod and was used for the estimates of comfortable walking speeds listed in Table 3.

According to the findings presented here, at comfortable walking speeds, stride frequency probably was about $10 \%$ or $20 \%$ below the natural pendulum frequency of the hindlimbs. The estimates of comfortable walking speeds of some Tendaguru-sauropods of typical size presented in Table 3 are based on the assumption that the stride period was about $10 \%$ above the natural pendulum period of the hindlimbs. At maximum speeds, the relative stride length of the hindlimbs

Table 3

Speed estimates for some Tendaguru-dinosaurs. h, estimated hip height of an adult specimen; $T$ estimated natural pendulum period; $T^{\prime}$, estimated stride period at comfortable walking speeds; $v$, estimated comfortable walking speed; $v^{\prime}$, upper speed limit. For further explanation see text.

\begin{tabular}{|c|c|c|c|c|c|c|c|}
\hline species & $\frac{\mathrm{h}}{\mathrm{m}}$ & $\frac{\mathrm{T}}{\mathrm{s}}$ & $\frac{\mathrm{T}^{\prime}}{\mathrm{s}}$ & $\frac{\mathrm{v}}{\mathrm{m} / \mathrm{s}}$ & $\frac{\mathrm{v}}{\mathrm{km} / \mathrm{h}}$ & $\frac{\mathrm{v}^{\prime}}{\mathrm{m} / \mathrm{s}}$ & $\frac{\mathrm{v}^{\prime}}{\mathrm{km} / \mathrm{h}}$ \\
\hline Brachiosaurus brancai & 3.5 & 2.7 & 3.0 & 1.2 & 4.2 & 4.7 & 16.9 \\
\hline Barosaurus africanus/Tornieria robusta & 2.4 & 2.2 & 2.4 & 1.0 & 3.6 & 3.9 & 14.0 \\
\hline Dicraeosaurus hansemanni & 2.2 & 2.1 & 2.3 & 0.95 & 3.4 & 3.7 & 13.4 \\
\hline Dicraeosaurus sattleri & 1.8 & 1.9 & 2.1 & 0.85 & 3.1 & 3.4 & 12.1 \\
\hline
\end{tabular}


probably was not greater than 2.0 (Thulborn 1990). As demonstrated above, equation (1) of Alexander (1976) seems more appropriate for estimates of maximum speeds and was used to calculate the estimated maximum speeds in Table 3 assuming a relative stride length of 2.0 in the hindlimbs.

Comfortable speeds of adult Tendaguru-sauropods probably were around 3 or $4 \mathrm{~km} / \mathrm{h}$ as in comfortable walking humans. Maximum walking speeds could have been much higher, comparable to comfortable running speeds in humans.

\section{Conclusions}

In the light of results presented here, speed estimates based on estimates of stride frequencies from fossil trackways seem less reliable for dinosaurs and other extinct terrestrial vertebrates than speed estimates which are based on relations among stride length, hip heights, and speed (Alexander 1976), or estimates of maximum speeds that are based on calculations of bone strength (Alexander 1985a, Farlow et al. 1995; but see also Alexander 1996).

Limb movements in dinosaurs may have departed considerably from a simple pendulum-like behaviour. However, taking hip accelerations and the special morphology of different dinosaurs into account, a reanalysis of limb swinging in large recent mammals may allow better estimates of speed and cost of transport in large dinosaurs. If a variety of trackways from a certain kind of track-maker are available, trackways with different stride lengths might be attributed to different stride frequencies making speed estimates more reliable. Long strides that indicate high rates of locomotion probably had a frequency between the natural pendulum frequency of the limbs and twice this frequency. Short strides indicate a lower stride frequency, possibly as low as half the natural pendulum frequency of the limbs. Mean stride lengths can be attributed to comfortable walking speeds with stride periods $10 \%$ or $20 \%$ above the natural pendulum periods of the limbs. The very different lengths of forelimbs and hindlimbs in some dinosaurs, however, make speed estimates more complicated. This anatomical feature implies very different natural pendulum periods of hindlimbs and forelimbs, respectively. It may indicate longer excursions of the shoulder joints compared to the hip joints during a stride, or forelimb move- ments that were not restricted to parasagittal planes.

Sauropods and probably other large dinosaurs usually walked at low speeds comparable to low walking speeds in humans. However, under certain circumstances, large dinosaurs might have been able to walk fast and economically using a similar mechanism to large terrestrial mammals like elephants and giraffes to shift energy from the trunk to the limbs by accelerating hip and shoulder joints.

\section{Acknowledgements}

The locomotion of elephants was studied in the Zoo Krefeld, Germany, with the help of Wolfgang Nehring. Net giraffes were studied in the Allwetterzoo Münster, Germany, with the help of K. Perret. Figures 2-5 are drawn by M. Wischniwetzki and $\mathrm{H}$. Schultze. We are very obliged to $\mathrm{R}$. McNeill Alexander for constructive and encouraging comments on a short version of the manuscript and to J. O. Farlow, M. B. Smith, and H.-P. Schultze for critical and constructive reviews of the manuscript. The study was supported by Deutsche Forschungsgemeinschaft (DFG), project SCHU 212/16-1.

\section{References}

Alexander, R. McN. 1976. Estimates of speeds of dinosaurs. - Nature 261: 129-130.

- 1985a. Mechanics of posture and gait of some large dinosaurs. - Zoological Journal of the Linnean Society 83: $1-25$.

- 1985b. Body Support, Scaling and Allometry. In Hildebrand, M., Bramble, D. M., Liem, K. F. \& Wake, D. B. (eds.). Functional Vertebrate Morphology: 26-37. Cambridge, USA (Harvard University Press).

- 1989a. Dynamics of Dinosaurs and Other Extinct Giants. 167 pp. New York (Columbia University Press).

- 1989b. Optimization and Gaits in the Locomotion of Vertebrates. - Physiological Reviews 69 (4): 1199-1227.

- 1995. Simple models of human movement. Applied Mechanics Review 48 (8): 461-470.

- 1996. Tyrannosaurus on the run. - Nature 379: 121.

Bakker, R. 1986. The Dinosaur Heresies: New Theories Unlocking the Mystery of the Dinosaurs and Their Extinction. 482 pp. New York, (William Morrow).

Biewener, A. A. 1989. Scaling body support in mammals: limb posture and muscle mechanics. - Science 245: 45-48.

- 1990. Biomechanics of mammalian terrestrial locomotion. - Science 250: 1097-1103.

Charig, A. J. 1979. A New Look at the Dinosaurs. 160 pp. London, (Heinemann).

Christian, A. 1995. Zur Biomechanik der Lokomotion vierfüßiger Reptilien (besonders der Squamata). - Courier Forschungs-Institut Senckenberg 180: 1-58.

Christiansen, P. 1997. Locomotion in sauropod dinosaurs. Gaia 14: 45-75.

Coombs, W. P., Jr. 1978. Theoretical aspects of cursorial adaptations in dinosaurs. - The Quarterly Review of Biology 53: 393-418.

Demathieu, G. 1986. Nouvelles recherches sur la vitesse des vertébrés, auteurs de traces fossiles. - Geobios 19: $327-333$. 
Demes, B. \& Günther, M. M. 1989. Biomechanics and allometric scaling in primate locomotion and morphology. Folia Primatologica 53: 125-141.

Farlow, J. O., Smith, M. B. \& Robinson, J. M. 1995. Body mass, bone "strength indicator", and cursorial potential in Tyrannosaurus rex. - Journal of Vertebrate Paleontology 15 (4): 713-725.

Fastovsky, D. E. \& Weishampel, D. B. 1996. The Evolution and Extinction of the Dinosaurs. 460 pp. Cambridge, USA (Cambridge University Press).

Hildebrand, M. 1985. Walking and running. In Hildebrand, M., Bramble, D. M., Liem, K. F. \& Wake, D. B. (eds.). Functional Vertebrate Morphology: 38-57. Cambridge, USA (Harvard University Press).

Hoyt, D. F. \& Taylor, C. R. 1981. Gait and the energetics of locomotion in horses. - Nature 292: 239-240.

Johnson, R. E. \& Ostrom, J. H. 1995. The forelimb of Torosaurus and an analysis of the posture and gait of ceratopsian dinosaurs. In Thomason, J. (ed.). Functional Morphology in Vertebrate Paleontology: 205-218. Cambridge, United Kingdom (Cambridge University Press).

Kram, R. \& Taylor, C. R. 1990. Energetics of running: a new perspective. - Nature 346: 265-267.

Langman, V. A., Roberts, T. J., Black, J., Maloiy, G. M. O., Heglund, N. C., Weber, J.-M., Kram, R. \& Taylor, C. R. 1995. Moving cheaply: energetics of walking in the African Elephant. - Journal of Experimental Biology 198: 629-632.

Lockley, M. G. 1991. Tracking Dinosaurs: A New Look at an Ancient World. 238 pp. Cambridge, United Kingdom (Cambridge University Press).

Lockley, M. G. \& Hunt, A. P. 1995. Dinosaur Tracks and Other Fossil Footprints of the Western United States. $338 \mathrm{pp}$. New York (Columbia University Press).

McGreer, T. 1990. Passive dynamic walking. - International Journal of Robotics Research 9 (2): 62-82.

- 1992. Principles of walking and running. In Alexander, R. McN. (ed.). Mechanics of Animal Locomotion. Advances in Comparative and Environmental Physiology: 113-139. Berlin (Springer).

McMahon, T. A. \& Bonner, J. T. 1983. On Size and Life. 255 pp. Scientific American Books, New York (W. H. Freeman).

Mochon, S. \& McMahon, T. A. 1980a. Ballistic walking. Journal of Biomechanics 3: 49-57.

- 1980b. Ballistic walking: an improved model. - Mathematical Biosciences 52: 241-260.
Paul, G. S. 1987. The science and art of restoring the life appearance of dinosaurs and their relatives. In Czerkas, $\mathrm{S}$. \& Olsen, E. (eds.). Dinosaurs Past and Present: 4-49. Los Angeles, USA (Natural History Museum of Los Angeles County).

- 1988. The brachiosaur giants of the Morrison and Tendaguru with a description of a new subgenus, Giraffatitan, and a comparison of the word's largest dinosaurs. - Hunteria 2 (3): $1-14$.

Preuschoft, H. \& Günther, M. M. 1994. Biomechanics and body shape in primates compared with horses. - Zeitschrift für Morphologie und Anthropologie 80 (1): 149-165.

Preuschoft, H., Witte, H. Christian, A. \& Recknagel, S. 1994. Körpergestalt und Lokomotion bei großen Säugetieren. Verhandlungen der Deutschen Zoologischen Gesellschaft 87 (2): $147-163$.

Schmidt-Nielsen, K. 1984. Scaling: Why is Animal Size so Important? 241 pp. Cambridge, United Kingdom (Cambridge University Press).

Taylor, C. R. 1977. The energetics of terrestrial locomotion and body size in vertebrates. In Pedley, T. J. (ed.). Scale Effects in Animal Locomotion: 127-141. London (Academic Press)

- 1994. Relating mechanics and energetics during exercise. In Jones, J. H. (ed.). Advances in Veterinary Science and Comparative Medicine, vol. 38A, Comparative Vertebrate Exercise Physiology: Unifying Physiological Principles: 181-215. San Diego (Academic Press).

Taylor, C. R., Heglund, N. C., McMahon, T. A. \& Looney, T. R. 1980. Energetic cost of generating muscular force during running. - Journal of Experimental Biology 86: 9-18.

Taylor, C. R., Heglund, N. C. \& Maloiy, G. M. O. 1982. Energetics and mechanics of terrestrial locomotion. I. Metabolic energy consumption as a function of speed and body size in birds and mammals. - Journal of Experimental Biology 97: 1-21.

Thulborn, R. A. 1990. Dinosaur Tracks. 410 pp. London (Chapman and Hall).

Weishampel, D. B., Dodson, P. \& Osmólska, H. (eds.) 1990. The Dinosauria. 733 pp. Berkeley, USA (University of California Press).

Witte, H., Preuschoft, H. \& Recknagel, S. 1991. Human body proportions explained on the basis of biomechanical principles, - Zeitschrift für Morphologie und Anthropologie 78 (3): 407-423.

Witte, H., Lesch, C., Preuschoft, H. \& Loitsch, C. 1995. Die Gangarten der Pferde: Sind Schwingungsmechanismen entscheidend? - Pferdeheilkunde 11 (3): 199-206. 